\title{
Depression, sexual dysfunction and medical comorbidities in young adults having nicotine dependence.
}

Dr Ranjan Bhattacharyya. MD, DNB, MNAMS. Associate Professor \& HOD, Department of Psychiatry, Murshidabad Medical College \& Hospital, West Bengal, India.

Dr Debasish Sanyal. MD. Professor, Department of Psychiatry, K.P.C. Medical College \& Hospital, Kolkata, India.

Dr Kaustav Chakraborty. MD DNB, MNAMS. Associate Professor \& HOD, Department of Psychiatry, College of Medicine \& JNM, Kalyani, Nadia, West Bengal, India.

Dr Rajarshi Neogi. MD. Assistant Professor, Department of Psychiatry, R. G. Kar Medical College \& Hospital, Kolkata, India.

\section{Background:}

Nicotine dependence, Depression, Diabetes mellitus, Hypertension, antihypertensive drugs and hypothyroidism are risk factors to cause sexual dysfunction and their relationship with depression is bi-directional ${ }^{1}$. The anti-depressants are known to cause sexual dysfunction too'.

\section{Aims \& Objectives:}

The present study aims to find out the prevalence of sexual dysfunction in the various sexual response cycle domains involved in subjects with nicotine dependence with and without comorbidities.

\section{Materials \& methods:}

The 52 subjects (age group 18-45 years) of both sexes attending the outpatient department (OPD) of a tertiary medical college \& hospital from India who had been referred from other departments for Erectile Dysfunction were included in the study. The three major comorbidities Hypertension, Type 2 Diabetes Mellitus and Hypothyroidism were enquired, investigated, assessed and correlated as secondary outcome measures.

To assess the primary outcome, Fagerstrom test for Nicotine dependence (FTND), Arizona Sexual Experiences Scale (ASEX), Hamilton's Depression Rating Scale (HAM-D 17) had been administered after validation in local vernacular.

\section{Results:}

The data was analysed by SPSS 15.0. The descriptive tables of the sample population, its clinical variables and correlations are depicted in the following tables.

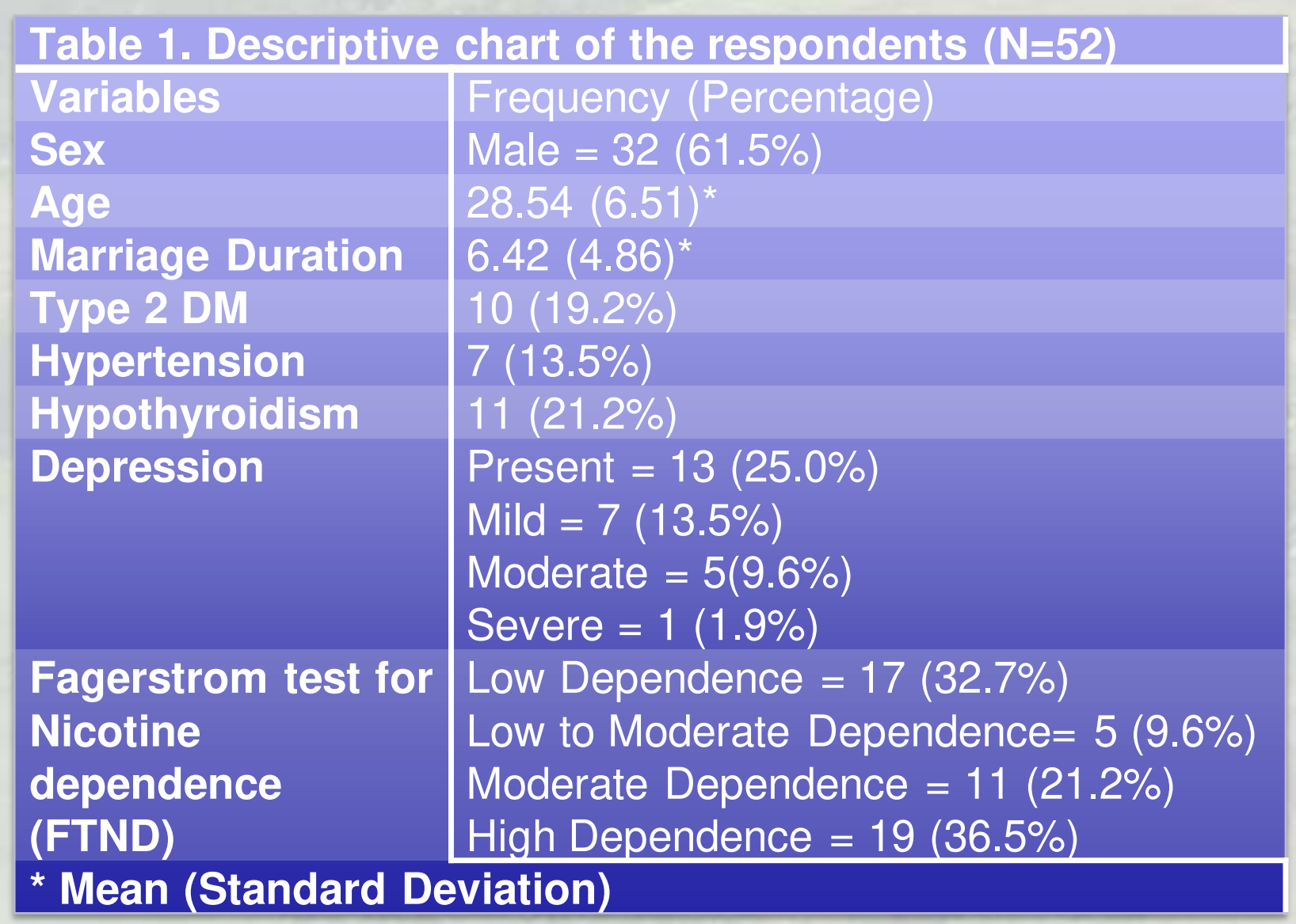

\begin{tabular}{lcc}
\multicolumn{2}{l}{ Table 2: Clinical Descriptive table: } \\
\hline Variable & Mean & Std Deviation \\
Depression (HAM-D) & 8.29 & 3.127 \\
ASEX\# Drive & 2.33 & 1.530 \\
ASEX\# Arousal & 2.42 & 1.526 \\
ASEX\# Erection & 2.87 & 1.692 \\
ASEX\# Orgasm & 2.92 & 1.667 \\
ASEX\# Satisfaction & 2.77 & 1.516 \\
ASEX Total & 13.31 & 7.280 \\
Fagerstorm Questionnaire & 5.92 & 3.767 \\
\#ASEX=Arizona Sexual Experiences Scale subscales score
\end{tabular}

The co-relation with the domains of sexual dysfunction measured with ASEX and the other co-relates viz. age, duration of marriage (Marriage), depression scores (measured with HAM-D) and the degree of Nicotine dependence (measured by FTND). Most of the correlates correlated significantly with the ASEX scores.

\begin{tabular}{|c|c|c|c|c|}
\hline & Age & Marriage & HAM-D 17 & FTND \\
\hline $\begin{array}{l}\text { ASEX } \\
\text { Drive }\end{array}$ & $0.590 \$ \$$ & $0.0743^{\$ \$}$ & $0.574^{\$ \$}$ & $0.668^{\$ \$}$ \\
\hline $\begin{array}{l}\text { ASEX } \\
\text { Arousal }\end{array}$ & $0.472 \$ \$$ & $0.576 \$ \$$ & $0.373^{\$ \$}$ & $0.726^{\$ \$}$ \\
\hline $\begin{array}{l}\text { ASEX } \\
\text { Erection }\end{array}$ & $0.434 \$ \$$ & $0.560 \$ \$$ & $0.434^{\$ \$}$ & $0.810^{\$ \$}$ \\
\hline $\begin{array}{l}\text { ASEX } \\
\text { Orgasm }\end{array}$ & $0.293^{\$}$ & $0.413^{\$ \$}$ & $0.309^{\$}$ & $0.830 \$ \$$ \\
\hline $\begin{array}{l}\text { ASEX } \\
\text { Satisfaction }\end{array}$ & $0.277^{\$}$ & $0.312^{\$}$ & 0.209 & $0.732 \$ \$$ \\
\hline ASEX Total & $0.449 \$ \$$ & $0.566 \$ \$$ & $0.414^{\$}$ & $0.823^{\$ \$}$ \\
\hline
\end{tabular}

\section{Conclusion:}

The Nicotine dependence is related to sexual dysfunction affecting various stages of sexual response cycle and is directly correlated with severity of nicotine dependence. One quarter of individuals of nicotine dependence also met the threshold criteria of depression. The interventions as primary and primordial preventions at Tobacco cessation unit with awareness building and health education may be a cost effective measure to prevent further comorbidities and tobacco related deaths. 